\title{
Media Innovations, User Innovations, Societal Innovations
}

\author{
Axel Bruns \\ ARC Centre of Excellence for Creative Industries and Innovation \\ Queensland University of Technology \\ a.bruns@qut.edu.au
}

\section{Introduction}

As the Journal of Media Innovations comes into existence, this article reflects on the first and most obvious question: just what do we mean by "media innovations"? Drawing on the examples of a range of recent innovations in media technologies and practices, initiated by a variety of media audiences, users, professionals, and providers, it explores the interplay between the different drivers of innovation and the effects of such innovation on the complex frameworks of contemporary society and the media ecology which supports it. In doing so, this article makes a number of key observations: first, it notes that media innovation is an innovation in media practices at least as much as in media technologies, and that changes to the practices of media both reflect and promote societal changes as well - media innovations are never just media technology innovations. Second, it shows that the continuing mediatisation of society, and the shift towards a more widespread participation of ordinary users as active content creators and media innovators, make it all the more important to investigate in detail these interlinked, incremental, everyday processes of media and societal change - media innovations are almost always also user innovations. Finally, it suggests that a full understanding of these processes as they unfold across diverse interleaved media spaces and complex societal structures necessarily requires a holistic perspective on media innovations, which considers the contemporary media ecology as a crucial constitutive element of societal structures and seeks to trace the repercussions of innovations across both media and society - media innovations are inextricably interlinked with societal

The Journal of Media Innovations 1.1 (2014): 13-27

(C) Axel Bruns 2014

http://www.journals.uio.no/index.php/TJMI 
innovations (even if, at times, they may not be considered to be improvements to the status quo).

Media reflect society not only in their content, but also in their organisational and technological structures. Media are part of society, however much some media professionals and organisations may wish to claim the status of independent, disinterested, unbiased observers; they are intermediate and do mediate between different parts of society, and as society changes, so do the media which are situated in between its constituent elements. In a very direct sense, therefore, when we examine media innovations we are really investigating one of the processes of societal innovation. But it is nonetheless useful to take the idea of media innovations as our starting-point, and to trace the processes of societal change from here: to do so provides us with an opportunity to unravel the network of interdependencies through which media, their (professional as well as amateur) users, and society at large are intertwined, and through which innovative ideas are communicated and generate change.

\section{Innovations in the media, by the media}

In the complex interplay between media and other societal actors, sometimes it is the media which lead such processes of change, and sometimes they lag behind other actors. To pick a handful of examples to illustrate this: in many countries the societal acceptance of demographic change - of a shift towards more multicultural, multi-ethnic societies - has predated its reflection on television screens, with newsreaders and actors remaining representative largely (even exclusively) of majority ethnicities; however, it may be argued that the introduction of public service television channel SBS (Special Broadcasting Service) in Australia during the 1980s, as a channel dedicated especially to the country's non-Anglo-Saxon minority communities (see e.g. Jakubowicz, 1987), is one example of a media innovation which predated or at least paralleled the growing acceptance of multiculturalism in that country during the latter decades of the twentieth century. (We may also suggest that this was less a media innovation in its own right than a political initiative which led to innovation in Australia's media landscape, however.)

If in the case of multicultural representation in the media, media innovation has largely followed societal change, in other cases we may observe - even without falling into the trap of purely techno-deterministic argumentation - how media innovation has driven societal change. Christoph Bieber, for example, has suggested that the arrival of WikiLeaks as a new and controversial model of a media organisation - in Jay Rosen's terms, "the world's first stateless news organisation" (2010) - has triggered various "dynamics of change" across the intertwined landscapes of media and society (Bieber, 2013, p. 324). Bieber sees WikiLeaks - the idea of WikiLeaks as much as the actual site itself - as triggering 
a range of profound changes and innovations in the media, in the professions which sustain the media, and in society's relations with the media: he believes, first, that the exponential multiplication of digital data on all aspects of society (in short, the rise of what has been summarised under the term 'big data' in recent years) "will be responsible for a future "economy of the leak" (ibid.) in which WikiLeaks-style data leaking platforms and facilities multiply both outside and inside conventional media organisations. Second, and to some extent as a direct consequence of the first point, professional roles in the media industry may have to adapt to an informational environment in which leaks play an increasingly important role: "leaking" may be seen as "a current embodiment of investigative journalism" (ibid.), a practice in which professional journalists work closely with leakers and even employ third parties as information couriers. The current Edward Snowden / David Miranda / Glenn Greenwald affair around information leaked from the US National Security Agency to The Guardian serves as one example of such change in journalist/non-journalist relations. This also already points to a third dimension of change, in "the consequences of the "logic of the leak' for the relationship between citizens and members of the political system" (Bieber, 2012, p. 324), including journalists. (Here we may also consider the persistent and repeated leaking of information on tax evaders from Swiss banks to German journalists and even German state authorities as another example of how entrenched the logic of the leak has become; cf. Spiegel, 2012.)

But an answer to the question of whether the chicken of media innovation or the egg of societal innovation came first is usually complex, and often irrelevant. Whistleblowing and leaks predate the arrival of WikiLeaks as a platform and organisation, but especially in marrying this older culture of leaking with current 'Web 2.0' technologies under the WikiLeaks moniker (with its mischievous and misleading allusion to the most famous wiki site, Wikipedia) the WikiLeaks project has arguably triggered more substantive change than individual leakers had managed to do before. It has brought what Bieber calls "the logic of the leak" into the media and societal mainstream with a force that appears to continue even where WikiLeaks itself, burdened by internal strife and a controversial leadership figure, is faltering. More recent high-profile leaks of sensitive information have drawn less on third-party intermediaries like WikiLeaks, and instead built on direct contacts between whistleblowers and leading news and government organisations: Edward Snowden's leaks about the US National Security Agency's widespread phone and Internet surveillance of citizens in the United States and 'friendly' nations, for example, have drawn directly on the resources of The Guardian and, more recently, the New York Times and Der Spiegel in making international news (Lawless, 2013); anonymous insider sources leaking the Swiss bank account details of major tax cheats even managed to sell their information directly to German tax investigators, causing a wave of new prosecutions for tax evasion in recent years (The Economist, 2013). From one perspective, this shows how successful WikiLeaks has been in highlighting the affordances of new media 
technologies in facilitating whistleblowing at an unprecedented scale, and thereby in establishing leaking as an acceptable if not uncontroversial response to corporate and governmental abuses of power. We may argue that media innovation is leading societal innovation, that the initiative of Julian Assange and his fellow grassroots activists has led to long-term change in media and society, even to the point where the initial catalyst for such innovation - WikiLeaks itself - is no longer at the forefront of these transformations. (That such change is not always a change for the better does not undermine this argument.)

\section{Media innovation from the edges}

It should not be overlooked that such change, such innovation, in the media often originates from the edges of the mainstream media system, where change is less encumbered by tradition, by an established way of doing things. WikiLeaks was the initiative of media outsiders who, based on their growing notoriety, were able to build at least temporary alliances with some very significant mainstream media outlets in a number of key countries; its whose operational logic has now been internalised at least by some of these partner organisations for their own investigative reporting - e.g., The Guardian, Der Spiegel, The New York Times but also other mainstream news organisations such as the Australian Broadcasting Corporation which now provide some supposedly secure "tip-off" functionality on their Websites, targeting would-be whistleblowers (e.g. ABC, 2013). In a manner of speaking, this represents a case of "innovation push" where a new media model is trialled and found to be workable and valuable, if not without adjustments. SBS, on the other hand, could be described as a form of "innovation pull", where a clearly perceived need for new approaches to television broadcasting leads to the development and gradual mainstreaming of an innovative public broadcasting setup that addresses the requirements of a changing society. SBS itself, of course, was not without its grassroots antecedents, in the form of small-scale community media servicing specific ethnic and cultural groups in Australian society (Ang et al., 2008).

Overall, then, perhaps an appropriate metaphor for this complex system of interaction between a society and its media is that like the Earth and its Moon, both revolve around a common barycentre that is situated between them; sometimes it is society and sometimes the media that drive processes of innovation and change, but both are inextricably interdependent on each other. But contrary to the comparatively stable Earth-Moon system, in the media-society system the shapes of the two bodies orbiting each other are constantly in flux, and thus always at risk of upsetting the delicate balance between them. The entrance of new players, the emergence of new practices, in the media industries has the potential to severely undermine existing arrangements, sending the entire system spinning out of control until a new equilibrium is established. 
Arguably, the past decades - since the advent of the World Wide Web and especially the growth of user-generated content, in a second stage of change have considerably sped up such developments. Several now dominant players in the global media landscape (Google, Facebook) barely even existed ten or fifteen years ago; they have developed rapidly, if not always steadily, from small-scale initiatives to corporate giants. But it is not simply the emergence of these companies and their products and services which is remarkable, but the way in which innovative processes have unfolded within and around them: rather than being driven simply by internal developments and corporate imperatives, media innovation in the Internet age is now largely a story of co-creation of products, platforms, and practices in collaboration between users and producers (cf. Banks, 2013; Bruns, 2008).

One of the more recent success stories, Twitter, may serve as a useful example in this context. The Twitter platform itself emerged in 2006 as a tool which enabled users to post short-message status updates to a loose network of connections, resembling in no small part a kind of public, group SMS-style format (indeed, the need to be able to post to Twitter from mobile phones via SMS is responsible in part for Twitter's 140-character message limit, since a single SMS is limited to 160 characters; cf. Rogers, 2013). As a communal platform for what has sometimes been described as "microblogging", the mere ability to post such short-form updates of one's current status may have been sufficient; however, Twitter's most enduring and distinctive communicative features, the @reply and hashtag, were user conventions - or indeed, inventions which considerably enhanced the flexibility and versatility of the service. As Halavais (2013; also cf. Bruns, 2012) shows, these innovations (which had their precedents in blogs and Internet Relay Chat, respectively) were introduced to Twitter by users who needed to do more than what the platform supported natively - they wanted to be able to address fellow users directly without retreating to the private, invisible sphere of direct messaging (via@replies), or to coordinate public discussions across large and previously unconnected groups of users interested in the same topics (using hashtags), for example. Twitter, Inc. only began to add formal support for such communicative elements when it became clear that they would play a significant role in user practices and the future development of Twitter as a platform for public communication. By now, such user-led platform innovation has even spread beyond Twitter itself, as Facebook, too, has introduced hashtagging functionality even though the smallworld, semi-private structure of its friending networks is comparatively ill-suited to benefitting from the use of hashtags (cf. Bosker, 2013).

If such examples demonstrate that media innovation, particularly but not only for predominantly online media, is now coming especially from the edges - in the form of entirely new media initiatives such as WikiLeaks, or in the form of usergenerated incremental innovation being incorporated into existing media platforms and organisations - then this further highlights the interdependent 
nature of media and societal innovations in the current era. User participation in, user co-creation of the media - for example through the processes of what I have described elsewhere as produsage (Bruns, 2008) - in a very real sense is both media and societal innovation, and arguably collapses the two categories into one: into multi-pronged innovative processes within a comprehensively mediatised society in which boundaries between media professionals and media amateurs are rapidly shifting, even dissolving.

Early in the 21 st century, facing a first wave of repercussions from this shift at a time when news bloggers and citizen journalists first began to question and deconstruct the professional authority of industry journalists, Jay Rosen coined the memorable term "the people formerly known as the audience" (2006) to describe these new actors in the media society, and Dan Gillmor suggested that the "readers know more than I do" (2003) on many specialist topics covered by generalist news reporters - but today, even the remnants of such 'us and them' conceptualisations of the professional/amateur divide are being eroded by contemporary patterns of information dissemination. Social media, for example, are rapidly taking on a key role as the new mechanisms through which many of us follow and engage with the news (see e.g. Holcomb et al., 2013, for recent US statistics on this trend), but they also atomise the news, and undermine the established structures of the news industry: we now encounter individual stories, even individual updates to continuing stories, from a wide range of sources rather than loyally subscribing to selected channels and publications; we follow individual journalists, and para-journalistic actors such as organisational spokespersons and individual domain experts, across a broad number of fields, rather than trusting only in the imprints of news organisations; and we engage with such actors on social media not as a receptive audience to a news provider, but as fellow users trying to collaborate on "working the story" (Bruns \& Highfield, 2013). The most respected, most influential news imprint in this environment is no longer a Times, CNN, or even Guardian, but an @acarvin - the Twitter account of NPR journalist Andy Carvin, whose curation of social media updates about the unfolding Arab Spring became a crucial source of information about the events (cf. Hermida et al., forthcoming).

\section{Media innovations and the media ecology}

Under these conditions, then, research into media innovations increasingly becomes research into societal change itself. The argument here is similar to that put forward by Richard Rogers when he calls on us to move from researching 'the Internet' to researching society with the Internet (2009): with the increasing embedding of Internet technologies into every aspect of our lives, the Internet no longer constitutes a separate (or separable) object of study, but rather becomes an integral element of society itself. Similarly, with the mediatisation of society at 
large - "the process whereby society to an increasing degree is submitted to, or becomes dependent on, the media and their logic" (Hjarvard, 2008, p. 113) -, not least but not only through the rise of user-led content creation and social media participation as examples of what Manuel Castells has called "mass selfcommunication" (2009), the study of media innovation is no longer a study of innovation in 'the' media, but of innovative practices of participating in society of societal change - itself.

Viewed from this perspective, however, the study of media innovations as societal change becomes a considerably more profound challenge. It is now no longer sufficient to tell the story of the functional innovations made to media platforms or practices by their operators or users - for example, to describe how Chris Messina's suggestion of using \#sandiegofire to track updates about a major wildfire in the U.S. helped to popularise the idea of Twitter hashtags (2007; also see Halavais, 2013), and to trace the technological antecedents and repercussions of this media innovation. Rather, a much more comprehensive history of change can and should be developed to fully understand the societal implications of media innovations, even where they are as deceptively simple an idea as the hashtag.

Social media analytics make it possible, of course, to engage in a programme of in-depth research into the uses of hashtags on Twitter and in other platforms, from their early applications in crisis communication (starting with the San Diego Fires) and other breaking news events (see e.g. Hermida, 2010; Bruns et al., 2012; Lotan et al., 2011) through an ever-widening range of other topical uses and on to the reappropriation of hashtags not to enable the gathering of a community of interest but rather to support memes and other virally distributed phenomena (cf. Leavitt, 2013). They even enable the observation of common patterns in hashtag use (Bruns \& Stieglitz, 2012; 2013), and other forms of research which explore the trajectories of the hashtag as an innovative and stillchanging element of social media communication. But where they focus only on what can be observed in and through the initial media space itself, such studies are unable to trace the wider social and societal trajectory of the hashtag outside of Twitter itself, a trajectory which is at least as fascinating and important for our understanding of its innovatory energy as the in-depth examination of practical uses of hashtags within Twitter.

Phenomena to consider in this context include, for example, the adaptation of hashtags into media platforms which do not or only in a very limited fashion support core hashtag functionality; this includes the appearance of hashtags in emails, SMS messages, or on Facebook, for instance. They also include the use of hashtags, and by extension of the Twitter platform as such, to promote backchannel mechanisms in radio and television broadcasting (Harrington et al., 2012), as visual elements in advertising, marketing, and public relations, and as slogans in political campaigns and public demonstrations. And they certainly also include the growing use of hashtags as flourishes in fashion and art. What has 
happened when the humble hashtag jumps its original technological boundaries in this way - when it appears on television screens, billboards, business cards, tshirts, tattoos, and more - is that it has emerged as a cultural phenomenon in its own right, detached or at least unlinked from Twitter itself, but at the same time also inherently demonstrating the transformational effects of Twitter in particular and of social media more generally on society at large. What started as a geeky, ad hoc technological innovation on an obscure social media platform has been transfigured into an icon of, indeed a symbol for, contemporary mediatised society.

In other words, if we thus consider media innovations to be more than simply changes in the practices and technologies which determine the uses of specific media - if instead we shift our perspective to the overall media ecology as such (that is, the interplay and interrelations of the various media technologies and practices through which a mediatised society operates), and aim to trace the changes to its overall dynamics which even small practical or technological innovations can cause, or if indeed we attempt to regard society as such, with the media as an integral part of society and an important driver of societal dynamics in a system of complex interdependencies - then research into the processes and consequences of media and societal innovation in this complex system requires the synthesis of a diverse range of approaches and observations. What becomes necessary is a close observation of the dynamics of specific media forms and platforms, as well as the comparison and correlation of observed phenomena across these platforms, combined with the development and evaluation of theoretical models which are able to make sense of these observations and retain the flexibility to account for further change.

The idea of a media ecology in which various species of media coexist and interact with, even interdepend on one another becomes a useful metaphor also for other reasons. It introduces a very long-term, evolutionary perspective of systemic change which sees some of the ecology's elements flourish while others struggle, but where reversals of fortune through the emergence of new threats or the adaptation to specific niches are also always possible. Many of the inhabitants of the media ecology, in fact, have proven remarkably adept at adjusting to new circumstances: as it appears from an early 21 st century perspective, few media forms ever go extinct completely, but they are at times forced to evolve rapidly in order to arrange themselves into new media-ecological niches, or take on new symbiotic or parasitical roles which subordinate them to currently flourishing species.

Perhaps the most famous media casualty of recent decades is the telegramme. India's shutdown of its 160-year-old telegramme service on 15 July 2013 became the cause for a world-wide wave of media coverage to mark the passing of this once so important global communications service (e.g. Pandey, 2013), and to reflect on its obsolescence at the hands of the telephone, email, and other less centrally controlled electronic and digital media. But if these 'new' media did 
indeed cause the extinction of the telegramme, they appear to have caused so gradual a death as to make it virtually indistinguishable from natural causes. Conversely, we might also ask whether the telegramme did indeed die at all, or whether its short, staccato message phrasing merely transmogrified into the even more shortened and stylised '133t speak' ["leet speak"] of more recent media such as SMS and Twitter, which appropriates and redeploys available punctuation, numerals, and ideogrammes to craft messages which, while at times incomprehensible to the uninitiated, convey all the more meaning to those who have learnt its codes. Media forms, in other words, are more than their technological infrastructure: just as importantly, they also describe a way of communicating - and the communicative practices of the telegramme, we might argue, have merely detached from one technological basis and migrated to other host technologies, in other niches of the global media ecology.

We have seen these processes played out over and over again in the recent past. The arrival of television and the VCR did not kill cinema, even in spite of the media panics which surrounded the introduction of such new media forms. CDs, DVDs, and then the various legal and illegal forms of delivering music in downloaded and streamed forms over the Internet did not kill vinyl records; indeed, even in spite of their obvious aural deficiencies vinyl LPs have now found a new, niche market as an audiophile specialty product and hipster status symbol. Vinyl products are now often packaged with free downloads of the album contents in digital form in order to facilitate both a sedentary and a mobile listening experience, resulting in an unexpected symbiosis between a threatened media species and its would-be predator. And even chemical photography has not been replaced entirely by its digital descendants, although some of the oncedominant commercial drivers of the former - most famously, the Kodak brand have been reduced to mere shadows of their former selves: electronics-free photography remains a viable niche pursuit, while a leading provider of digital photography services, Instagram, has built its billion-dollar market valuation chiefly on the premise of simulating the experience of chemical photography with all its visually attractive glitches and flaws. Here, too, tangible media technology and the material media experience which such technology has traditionally provided have detached from one another; while the former might indeed be threatened by gradual obsolescence, the latter has been adapted to and simulated by, and arguably is even further enhanced by, its new digital foundation.

The underlying process of such dynamic interactions between media forms within the overall media ecology is what Bolter \& Grusin (1999) have described as remediation:

In the first instance, we may think of something like a historical progression, of newer media remediating older ones and in particular of digital media remediating their predecessors. But ours is a genealogy of affiliations, not a linear history, and in this genealogy, older media can also remediate newer ones. (1999: 55) 
While, as Bolter \& Grusin note, a remediation of newer practices by older media remains possible, it is difficult to argue against the view that at present, the overwhelming push of remediation is towards the digital, with online and mobile media remediating older, offline and stationary practices. In the course of such remediation, media technologies and media practices appear increasingly detached from one another: a handful of foundational technological bases - the Internet and its underlying network infrastructure and protocols, as well as a small and shrinking number of competing device platforms (PCs, Macs, Linux; iOS and Android hand-held devices; and games consoles) - now provide a universal and standardised layer of media infrastructure that supports a very wide range of media practices. Such remediation further extends the reach of the latest wave of the mediatisation of society: as older media practices are remediated by newer, digital media, the inherent logics of these digital media - not least of which are their default commercial, social, and ethical configurations - are also spread further throughout society. In the process, for example, amateur creative works are repositioned as commercially exploitable, personal thoughts as publicly shareable, and private information as a tradeable commodity.

Apple's iPod, iPhone and iPad catchphrase "there's an app for that" neatly encapsulates this trend: its iDevices constitute a standard hardware and firmware platform that exists in only a small number of largely compatible variations, and it is this universal, versatile, tightly controlled hardware basis which has enabled the development of a galaxy of applications - many of which, importantly, remediate other, earlier, media practices from scribbling on paper through listening to radio and watching television to making telephone and videophone calls. Whichever extant medium you seek to remediate, to translate to a modern technological framework, to bring under Apple's commercial umbrella - there's an app for that. Other manufacturers have sought to do the same in the past (including Microsoft with Windows and a procession of games companies with their consoles), but few have been as successful.

It is beyond the scope of this article to discuss in detail the reasons for the success of iOS (and similarly, Android) devices in providing a unified technological infrastructure supporting a diverse range of use practices; we might speculate, however, that overall developments in computing technology have now reached the point where the possibilities even of comparatively cheap end-user technologies have surpassed the imagination of most users and software developers, in line with Moore's Law and similar development trends - in other words, while earlier generations of hardware never quite managed to live up to the uses we imagined for them, leaving users frustrated, our current hardware provides more capability than the average user is likely ever to need in their dayto-day media practice. While earlier, the pull of innovation in media practices led to rapid advances in media technology in order to keep up with what we wanted our devices to be able to do, now the push of innovation in media technology is 
encouraging us to dream up new media practices that make full use of the features available to us. We see this, for example, in the increasingly innovative uses of the haptic interfaces, movement sensors, and close-range communication technologies built into the current generation of mobile and portable devices.

These observations, then, provide further support to the argument that innovation in media technologies and innovation in media practices are increasingly decoupled from one another. Technological innovation is proceeding apace, but seems to be predate (and create) rather than respond to a mass market demand; the arms race especially between the leading portable device manufacturers has already resulted in a generation of devices whose capabilities are well ahead of the demand curve, for example, and whose further development shows little sign of slowing down. Under these circumstances of comparative technological abundance, then, it is innovation in media practices - in how such technologies are actually used - which becomes the central bottleneck, the central factor in determining the shape of the contemporary media ecology. How, in short, do media organisations, media producers, media users utilise the tools now available to them; how do they transform these technologies in the process of adoption; and how does this affect the overall balance of competing interests within the wider media ecology?

\section{Conclusion: Media innovation is societal innovation}

Although the role of technology must never be ignored or taken for granted, and although innovation in media technologies remains an important field of research in its own right, then, it is nonetheless likely that it is innovation in media practices - innovation driven as much by professional media practitioners as by the audiences and users of media - which will prove to have the more immediate impact on the further evolution of the contemporary media ecology. At a time of relative media technology abundance, at least in developed nations, we are more able than ever to make our own media, and this is borne out by the rapid and transformational rise of user-generated content as well as by the fast succession of new and significant media and communication platforms from email to Skype and from homepages to Twitter. (The fact that these examples, and many more beside them, are inherently based on Internet infrastructure both indicates the fundamental role which online technologies now play in the contemporary media environment and demonstrates the high degree of malleability which they have retained for everyday practical use.) If it is today predominantly an innovation in media practices, media innovation is now a matter for established media organisations, for emerging developers and entrepreneurs, and for loose communities of everyday users alike, and indeed - as the example of Twitter above shows - often driven by the interplay of all three forces. 
Such broad-based media innovation, then, is necessarily also a form of social and societal innovation. While the specific role of social media, defined narrowly as Facebook, Twitter, and similar platforms, is often overstated, all media are inherently social, and with continuing innovation in contemporary media practices the social aspects of media are becoming increasingly difficult to ignore. Especially as they are transitioned to and remediated through online channels, older media forms such as print and broadcast gain additional elements of sociality: they are shared, commented upon, and reappropriated by users, who thereby diminish and even eradicate the traditional distinctions between media producers and media audiences. Newer forms of media, on the other hand, increasingly start out without such in-built differences in the first place: media which are social by design, from Facebook to Pinterest, extend an open invitation to potential participants regardless of their prior histories of media content use and creation. These platforms, by contrast, anticipate the emergence of new roles and structures as an inevitable result of the social processes which take place amongst their userbase: depending on their contribution and commitment, some users will almost necessarily emerge as more central to the community than others. (The same process takes place, though potentially overlaid and encumbered by persisting legacy structures, as older media are remediated in new environments: hence the emergence of Andy Carvin as a news media organisation in his own right during the Arab Spring, as discussed above.)

If such social processes, such gradual reorganisations of existing structures and formations of new structures, take place at a smaller scale around individual media practices and platforms, however, then cumulatively they also combine to drive much wider, societal-scale changes and innovation. As our individual and collective media practices change, as the ways our media operate - or the ways we operate our media - evolve, our overall media ecology is disrupted and must find a new equilibrium. Our media, media practices, social practices, and society itself are inherently and inextricably entwined in contemporary mediatised society, however - a change to any one of these components will therefore necessarily also cause changes to the others. Innovation in media practices, then, is inevitably also a source of social and societal change - but whether media innovation is also societal innovation (in the narrow sense of "innovation" as "improvement") still remains to be seen.

Finally, then, if the three types of innovation discussed here - media innovation, user innovation, and societal innovation - are inherently layered upon and interleaved with each otherwhat value is there in distinguishing them; indeed, does a Journal of Media Innovations make sense? Here, we must recognise that interconnection does not imply homology. Media innovation may be a form of societal innovation, but not all societal innovation is driven by changes in the media; indeed, as we have seen above, some media-independent societal changes eventually cause further media innovation, too. It is precisely the identification of innovations in media practices and technologies, innovations in the activities and 
attitudes of media users, and innovations in wider societal processes and structures as distinct but connected components of a larger system (of the media ecology, from one perspective, or of mediatised society, from another) which enables us to trace the dynamics of their interplay and to understand how change and innovation in any one of these three components comes about. A Journal of Media Innovations, therefore, while focussing in the first place on the changing practices and technologies of the media as such, has much to offer in advancing our understanding of social and societal processes as well.

\section{References}

Ang, Ien, Gay Hawkins, and Lamia Dabboussy. (2008). The SBS Story: The Challenge of Cultural Diversity. Sydney: University of New South Wales Press.

Australian Broadcasting Corporation (ABC). (2013). Send Tip-Off. http://www.abc.net.au/news/contact/tip-off/

Banks, John. (2013). Co-Creating Videogames. London: Bloomsbury Academic.

Bieber, Christoph. (2013). Lessons of the Leak. A Companion to New Media Dynamics. Eds. John Hartley, Jean Burgess, and Axel Bruns. Malden, MA: Blackwell, pp. 322-336.

Bolter, Jay David, and Richard Grusin. (1999). Remediation: Understanding New Media. Cambridge, MA: MIT P.

Bosker, Bianca. (2013, 12 June). Facebook Introduces Hashtags, Moving Away from Friends. Huffington Post.

http://www.huffingtonpost.com/2013/06/12/facebookhashtags_n_3429743.html

Bruns, Axel. (2012). Ad Hoc Innovation by Users of Social Networks: The Case of Twitter. ZSI Discussion Paper 16 (2012). https://www.zsi.at/object/publication/2186

Bruns, Axel. (2008). Blogs, Wikipedia, Second Life, and Beyond: From Production to Produsage. New York: Peter Lang.

Bruns, Axel and Tim Highfield. (2012). Blogs, Twitter, and Breaking News: The Produsage of Citizen Journalism. Produsing Theory in a Digital World: The Intersection of Audiences and Production. Ed. Rebecca A. Lind. New York: Peter Lang, pp. 15-32.

Bruns, Axel and Stefan Stieglitz. (2013). Towards More Systematic Twitter Analysis: Metrics for Tweeting Activities. International Journal of Social Research Methodology, vol. 16, no. 2, pp. 91-108. 
Bruns, Axel and Stefan Stieglitz. (2012). Quantitative Approaches to Comparing Communication Patterns on Twitter. Journal of Technology in Human Services, vol. 30, no. 3-4, pp.160-185.

Bruns, Axel, Jean Burgess, Kate Crawford, and Frances Shaw. (2012). \#qldfloods and@QPSMedia: Crisis Communication on Twitter in the 2011 South East Queensland Floods. Brisbane: ARC Centre of Excellence for Creative Industries and Innovation. http://cci.edu.au/floodsreport.pdf

Castells, Manuel. (2009). Communication Power. Oxford: Oxford UP.

Economist, The. (2013, 19 Oct.). Hervé Lifting: A Five-Year-Old Revelation Continues to Vex Tax Cheats. http://www.economist.com/news/finance-andeconomics/21588136-five-year-old-revelation-continues-vex-tax-cheats-hervlifting

Gillmor, Dan. (2003). Foreword. We Media: How Audiences Are Shaping the Future of News and Information. Eds. Shane Bowman and Chris Willis. Reston, Va.: The Media Center at the American Press Institute. http://www.hypergene.net/wemedia/download/we_media.pdf

Halavais, Alexander. (2013). Structure of Twitter: Social and Technical. Twitter and Society. Eds. Katrin Weller, Axel Bruns, Jean Burgess, Merja Mahrt, and Cornelius Puschmann. New York: Peter Lang, pp. 29-42.

Harrington, Stephen, Tim Highfield, and Axel Bruns. (2012). More than a Backchannel: Twitter and Television. Audience Interactivity and Participation, ed. José M. Noguera. Brussels: COST Action Transforming Audiences, Transforming Societies, pp. 13-17. http://www.cost-transformingaudiences.eu/system/files/essays-and-interview-essays-18-06-12.pdf

Hermida, Alfred, Seth C. Lewis, and Rodrigo Zamith. (forthcoming). Sourcing the Arab Spring: A case study of Andy Carvin's sources on Twitter during the Tunisian and Egyptian revolutions. Journal of Computer-Mediated Communication.

Hermida, Alfred. (2010). From TV to Twitter: How Ambient News Became Ambient Journalism. M/C Journal, vol. 13, no. 2. http://www.journal.mediaculture.org.au/index.php/mcjournal/article/view/220

Hjarvard, Stig. (2008). The Mediatization of Society: A Theory of the Media as Agents of Social and Cultural Change. Nordicom Review vol. 29, no. pp. 105134.

Holcomb, Jesse, Jeffrey Gottfried, and Amy Mitchell. (2013, 14 Nov.) News Use across Social Media Platforms. Pew Research Journalism Project. http://www.journalism.org/2013/11/14/news-use-across-social-mediaplatforms/

Jakubowicz, Andrew. (1987). Days of Our Lives: Multiculturalism, Mainstreaming and 'Special' Broadcasting. Media Information Australia no. 45, pp. 18-32. 
Lawless, Jill. (2013, 3 Dec.). Guardian: We Have Published 1 Pct of Snowden Leak. Associated Press: The Big Story. http://www.bigstory.ap.org/article/guardian-we-have-published-1-pctsnowden-leak

Leavitt, Alex. (2013). From \#FollowFriday to YOLO: Exploring the Cultural Salience of Twitter Memes. Twitter and Society. Eds. Katrin Weller, Axel Bruns, Jean Burgess, Merja Mahrt, and Cornelius Puschmann. New York: Peter Lang, pp. 137-154.

Lotan, Gilad, Erhardt Graeff, Mike Ananny, Devin Gaffney, Ian Pearce, and danah boyd. (2011). The Arab Spring: The Revolutions Were Tweeted: Information Flows during the 2011 Tunisian and Egyptian Revolutions. International Journal of Communication, vol. 5, pp. 1375-1405.

Messina, Chris. (2007, 22 Oct. ). Twitter Hashtags for Emergency Coordination and Disaster Relief. Factory City.

http://factoryjoe.com/blog/2007/10/22/twitter-hashtags-for-emergencycoordination-and-disaster-relief/

Pandey, Geeta. (2013, 13 July). Telegrams STOP: End of Service Delivering Joy and Heartache. BBC News. http://www.bbc.co.uk/news/magazine-23271384

Rogers, Richard. (2013). Debanalising Twitter: The Transformation of an Object of Study. Twitter and Society. Eds. Katrin Weller, Axel Bruns, Jean Burgess, Merja Mahrt, and Cornelius Puschmann. New York: Peter Lang, pp. ix-xxvi.

Rogers, Richard. (2009). The End of the Virtual: Digital Methods. Inaugural lecture, University of Amsterdam, 8 May 2009. http://www.govcom.org/publications/full_list/oratie_Rogers_2009_preprint.p df

Rosen, Jay. (2010, 26 July). The Afghanistan War Logs Released by Wikileaks, the World's First Stateless News Organization. PressThink: Ghost of Democracy in the Media Machine. http://archive.pressthink.org/2010/07/26/wikileaks_afghan.html

Rosen, Jay. (2006). The People Formerly Known as the Audience. PressThink: Ghost of Democracy in the Media Machine. http://archive.pressthink.org/2006/06/27/ppl_frmr.html

Spiegel, der. (2012, 4 Dec.). Stashed in the Alps: A Tax Evasion Bonanza Hidden in a Swiss Bank. http://www.spiegel.de/international/germany/german-cityfinds-3-billion-euros-hidden-by-tax-evaders-in-swiss-bank-a-870831.html 